\title{
Improvement, trust, and the healthcare workforce
}

\author{
D M Berwick
}

Qual Saf Health Care 2003;12(Suppl 1):i2-i6

Although major defects in the performance of healthcare systems are well documented, progress toward remedy remains slow. Accelerating improvement will require large shifts in attitudes toward and strategies for developing the healthcare workforce. At present, prevailing strategies rely largely on outmoded theories of control and standardisation of work. More modern, and much more effective, theories of production seek to harness the imagination and participation of the workforce in reinventing the system. This requires a workforce capable of setting bold aims, measuring progress, finding alternative designs for the work itself, and testing changes rapidly and informatively. It also requires a high degree of trust in many forms, a bias toward teamwork, and a predilection toward shouldering the burden of improvement, rather than blaming external factors. A new healthcare workforce strategy, founded on these principles, will yield much faster improvement than at present.

See end of article for author's affiliation

Correspondence to:

Correspondence to:
D M Berwick, Institute for Healthcare Improvement, 375 Longwood Avenue, 4 th Floor, Boston, MA 02215, USA.

dberwick@ihi.org
Q uality and trust are first cousins. A mechanic who fixes a car builds the customer's trust; a doctor who relieves suffering earns the patient's trust. When these would-be helpers do not deliver on their promises, explicit or implied, trust decays. The fastest and best way to improve the public's trust in health care may be to improve its performance. Results build trust.

But performance improvement, to put it mildly, is difficult. If it were easy, we would not suffer from the serious quality problems that continue to plague medicine in America, the United Kingdom, and elsewhere. Study after study during the past 40 years has documented the system's gaps and failings. ${ }^{1}$ It is beyond the scope of this article to examine these quality problems in detail. The Institute of Medicine Roundtable lumped many of them into three categories: overuse of procedures that do not help people get better; underuse of procedures that can help; and misuse, or errors. ${ }^{2}$

Overuse, underuse, and misuse are mainly variations in the processes of care, and these apparently lead to variations in outcome. For example, the Cystic Fibrosis Foundation in the United States collects data on most patients with the disease who are treated in 160 American cystic fibrosis centres. The variation in outcomes among these centres is striking. Nationally, for example, about $26 \%$ of children with cystic fibrosis are below the tenth percentile for weight.
Yet the range among centres is $7.4-60.0 \%$. Nationally, the average FEVl (a measure of lung function) is $73.5 \%$ of the predicted normal value. Yet individual centres range from an average of $70.1-104.4 \%$ for children aged $6-13$, and from $40.0-85.8 \%$ for adults aged $18-30 .^{3}$

Recent analyses of large United States databases by Professor Brian Jarman suggest that case mix adjusted standardised mortality rates in American hospitals (on a scale where 100 represents the national average) range from near 40 to over 160 , a difference of $400 \%{ }^{4}$

Yet despite the evidence of defects and the tantalising promise that some among us excel and could be teachers to us all, changing healthcare systems to make them better has proven disappointingly challenging, cumbersome, and time consuming. Perhaps focusing on improving trust might play a key role in facilitating the process of change.

\section{CHANGING THE SYSTEM AS THE ROUTE TO IMPROVEMENT}

Health care is an emotionally charged part of the economy and society; almost everyone cares about it. Sociologically, it is a deeply entrenched system of institutions and behaviours. Moreover, providing health care is a difficult, demanding job, and not just for clinicians. Healthcare workers of all sorts, from managed care executives to hospital orderlies, operate in a fishbowl characterised by high expectations, deep personal commitment, and low tolerance for error. In such a high voltage context, almost any proposal for change leads to sparks.

And yet, change is possible. Other industries almost as large and as cumbersome as health care have changed substantially during the past couple of decades. American automobile manufacturers, for instance, reorganised production fundamentally in response to the onslaught of competition from Japan. Indeed, much of manufacturing worldwide today works on principles very different from, and much more effective than, those of a few decades ago. ${ }^{5}$

At the heart of a scientifically grounded theory for improving health care is the premise that quality is a system property, and that, therefore, what primarily determines the level of performance is the design of a healthcare system, not simply the will, native skill, or attitude of the people who work in that system. This is a relatively rare insight in a world strongly biased toward individual accountability and, when things go wrong, toward blame. To be sure, clear minds must acknowledge the existence of a few "problem doctors" and a few badly run healthcare institutions. None the less, the most 
effective route to improvement is through changing systems, not yelling at them.

The notion that quality is a system property may be a bit counter cultural, but it is not hard to grasp. It is obvious that any specific automobile has a certain top speed. That top speed characterises the automobile. A person displeased with his/her car's top speed is fully entitled to get angry at the car, to give it incentives to go faster, or to put an incident report in the car's file. But none of this, of course, will matter; the car will still never go faster than it is inherently able to. A driver who wants to go faster is going to need a different car. So it is with variations in the quality and results of care. The mortality rate of a specific hospital, the preservation of FEVI in a specific group of children with cystic fibrosis, or, indeed, any other outcome at all is a property of the existing system at work. As I have written elsewhere, "every system is perfectly designed to achieve exactly the results it gets", a statement I have called the first law of improvement. ${ }^{6}$ If we want a better result we will have to change the system.

How do we change a system, especially one as large and entrenched as health care? Three preconditions seem helpful: to face reality, to seek new designs, and to involve everyone. Facing reality means identifying the gap between current performance and the performance we desire. Without knowledge of the gap, will for change cannot develop. New designs are the way out of the bondage of the status quo. Involvement of many helps assure that the best possible new designs are found, adapted, and deployed. An individual can improve at playing tennis or learning Spanish on their own, but health care is inherently an interdependent system, usually beyond the reach of anyone acting alone to change it. Alone, as individuals, healthcare practitioners cannot often lower mortality rates or cut costs or reduce error rates. They need to work on the problem of improvement together. They are a team, whether they know it or not. ${ }^{7}$

Because the improvement of health care is a team effort, the issue of trust comes to the foreground. Many forms of trust are relevant to improvement: trust that the future can be better than the present; trust in patients and families, allowing us to hear their needs as legitimate and reasonable; and trust in our own capacities to learn and change, even in a hostile environment. People in health care, like people everywhere, may find it easier to blame others for their troubles, and health care has many promising targets for blame: insurance companies, the government, regulators, lawyers, and the media. However, the responsibility to change health care belongs to those who provide and manage it.

To shoulder that responsibility requires one final element of trust-trust in the workforce. This is the subject we will examine in the remainder of this article. Our premise is this: to achieve the health care we want, we will have to reenvision, and largely re-train, the healthcare workforce, so that they can become citizens in the improvement of their own work.

\section{BEYOND TAYLORISM}

Change in the workplace is handicapped by a widespread, though usually implicit, theory of production-a theory of the workforce. The theory is often called Taylorism, after Frederick W Taylor, although in many ways the label is unfair. Taylor's thinking was complex and deep, and his aims were often laudable. The management system that bears his name does not do the man justice. But if we want to understand how the workplace needs to be changed, we must understand and call into question many of the principles of Taylorism. $^{8}$

Frederick W Taylor was born in 1856 to a well to do Philadelphia family. Unlike other young men of his background, he dropped out of college and went to work in a metal products factory as a machinist. In the course of his career he became a self taught industrial engineer, eventually achieving a path finding insight about production and production workers. At the time, industrial production was new. Much of the work done in factories was based on an earlier "craft" model of production-skilled employees performed a variety of tasks, often fabricating entire products from start to finish. Taylor realised that if the work could be subdivided into highly specialised tasks, then less skilled people, the workers (rather than craftsmen), could staff the production line. He also measured the time employees took to perform their tasks and, based on his findings, he learned how to arrange the sequence of work so as to maximise the output of each person and of the factory as a whole. Scientific management, as his system came to be known, rigorously separated the planning of the work, done by engineers such as Taylor himself, from the execution of the work, which was carried out by ordinary frontline employees. To make scientific management effective, workers on the shop floor were to perform their tasks as fast as they could and exactly as they were told, no more and no less.

Scientific management was a momentous achievement, but it came at a high price to the nature of work itself. As Charlie Chaplin showed us, with agonising clarity, in his classic film Modern times, each worker became no more than a pair of hands. Taylor himself was deeply respectful of labour and labourers, and indeed viewed his system as enabling workers to attain a higher standard of living than they otherwise could. However, he wanted them to express their individuality at home, not at work. In the factory, the worker's job was to follow the rules as spelled out in manuals and enforced by supervisors. If a worker had an idea about how to build a better axle, he should keep it to himself; after all, the new axle might not fit the standard. Innovation would occur, of course, but that was the responsibility of the engineers, scientists, and planners, not the production workers.

Assuring quality of the manufactured products was primarily the responsibility of inspectors. In 1925 a quarter of the employees at Western Electric Labs (which made telephone equipment) were inspectors. The inspection system worked well enough; quality was fairly good, but it was stable. Its rate of improvement depended on the laboratories, not on the workforce.

Health care came late to the Taylorist party. For most of the 20th century, the model for healthcare delivery was very much a craft model. Individual doctors would treat the patients using their professional skills, experience, and judgment. In the 1980s, encouraged by the movement toward evidence-based medicine, healthcare leaders and regulators became interested in developing detailed protocols for care, creating Taylor like standards for many procedures. The Harvard anaesthesia guidelines, for instance, would make Taylor proud, spelling out a precise series of steps for anaesthesiologists to follow: connect the oxygen, do not leave the room, and so on. ${ }^{9}$ Much of this helped improve care and no doubt, many parts of medicine should be Taylorised. No parents want an anaesthesiologist experimenting with new and untried procedures when their child is in the operating room. Health care, a Baldrige award judge said to me in 1989, "has discovered Frederick Taylor and fallen in love".

But while health care was discovering Taylorism, other industries were moving beyond it, into more effective terrain. The car industry is a notable example. Influenced and threatened by the Japanese, car companies and other large manufacturers began experimenting with a different approach to work and the workplace. The key principles of this new approach are in many ways the exact opposite of 
what Taylor and his disciples taught. Taylor and Ford expected every customer to take what they produced ("the customer can have any color Model T he likes as long as it's black" was Ford's famous dictum). In the new view, every customer is an individual with individual needs and preferences, and quality consists of meeting those needs and preferences. Taylor and Ford assumed that there was a trade off between quality and cost. In the new view, improving quality often is the best way to reduce costs.

The post-Taylor view reconceptualises the employee's ideal role. Taylor espoused only one basic role for employees-read and follow the manual. Understand what you are supposed to do, and do it. The post-Taylor view suggests that good ideas for process improvement can come from anyone, and that the more ideas that are available, the easier it will be to find ways to improve processes. Because the best foundation for change is trying something, measuring the result, and learning from the measurement, the employee ends up being a real time scientist, practicing what might be called pragmatic or real time science aimed at making the work continually more productive. ${ }^{10}$ For the post-Taylor leader who values improvement, a key question is, "How can the workforce be helped to help?" Taylor focused on the design of work; post-Taylor leaders focus on the development of the workforce.

\section{A MODEL FOR IMPROVEMENT AS A GUIDE TO DEVELOPING THE WORKFORCE}

Understanding that the workforce needs to be engaged in the process of change is only the first step. The theory does not tell one how to go about it. A more specific "model for improvement" helps as a guide to workforce development. One of the simplest and best was laid out some years ago by the quality expert Thomas W Nolan and his colleagues. ${ }^{11}$ That model begins with three questions:

- What are we trying to accomplish?

- How will we know that a change is an improvement?

- What changes can we make that will result in an improvement?

Once a team has answers to these questions, it can run tests of change to see what works and what fails to work. We will examine each question in turn, and thereby clarify an image of the healthcare workforce of the future.

\section{What are we trying to accomplish}

All improvement requires a goal, an aim that is essentially the same as facing reality, mentioned above. Nobody learns Spanish until they acknowledge that they do not already know Spanish and decide that they would like to. In a Taylorist workplace, the workforce by definition has no aim other than getting the job done and collecting a pay check. In a post-Taylorist workplace, the workforce also has to develop the skill of identifying and agreeing on what they are going to make better.

Agreeing on aims for improvement is no small matter. An organisation's leaders must recognise and acknowledge the difference between where the organisation is and where it wants to be. That gap must be measured and communicated publicly. Workers and leaders can often best find the gaps that matter by listening very carefully to the people they serve-patients and families. The goal is to study the effect of the organisation's work on the people it is trying to help. That search-the search for the gap-requires an unusually high level of trust. There is no point in asking somebody "how are we doing?" if one does not trust their answer.

Another way to find gaps is to scrutinise data on performance. Any cystic fibrosis centre in the Cystic
Fibrosis Foundation's database, for instance, can compare the percent of its children under the tenth percentile for weight with the other centres. The difference between its own results and those of the best performer can become an embarrassment, a public relations problem, or, in the ethos of improvement, an aim. Of course, only fools would choose the third if they did not trust their own capacity to improve.

Whenever anyone proposes an improvement in a complex system, competing ideas inevitably emerge about what else should be improved. The Institute of Medicine's report, Crossing the quality chasm, itself listed six categories for improvement: safety, effectiveness, patient centredness, timeliness, efficiency, and equity. 'Within one hospital, different people will have different preferred aims, for example, reduce infections, reduce waiting times, and improve cardiac care. The list of candidates is endless, but improvement requires some degree of focus. Therefore, part of developing skill to improve in the workforce is to foster the ability to confront and resolve disagreement about what ought to be done first. That, too, involves trust.

How will we know that a change is an improvement All improvement is change, but not all change is improvement, therefore the model for improvement includes measurement-a way to know which changes help, and which do not. Interpreting measurements requires both skill and courage. The relevant skills are primarily those that allow one to sort a meaningful signal from background noise. The key issue here is, can the data be trusted? Is a change from $8-10 \%$ random or real? What extraneous factors, other than the change being tested, ought to be taken into account? How can a graph over time help? How can we measure several important variables at once, without becoming overwhelmed by numbers? Simple statistical skills, unnecessary in the Taylor era, are essential in helping a post-Taylor workforce contribute to improvement. ${ }^{12}$ Equally important are narratives and stories, which people involved in improvement in complex systems must be able to exchange to maximise their learning and increase their wisdom, a capacity that Karl Weick, a student of high reliability organisations, calls collective mindfulness. ${ }^{13}$

\section{What changes can we make that will result in improvement}

The third part of the model is actually to identify an alternative to the status quo that is worth trying out. An improvement oriented cystic fibrosis centre curious to know why its performance is not at the top of the distribution would, of course, promptly study the higher performing centres to see what they do differently.

There is no way around this search. Trust is central to this entire endeavour. Questions that are asked with distrust, jealousy, or defensiveness will not be authentic. Also, the answers will not be listened to. As a consequence, it cannot usually be done effectively or efficiently by third parties, no matter how eminent. It has to be done by the people who are trying to improve themselves, and it is often best done in groups. This comparative information cannot be gathered in secret either. The exchange of information has to be open, and it has to be two way, to enrich the knowledge of both those studying and those being studied. The fundamental skill here is best thought of as authentic curiosity as distinguishable from mere compliance or check list thinking. Curious seekers, on the lookout for changes worth testing, genuinely ask, how do you really do this? How do you do so much better than we do? They must mean it, and they must want to hear the answer.

Searchers for better ideas than the status quo must cast a wide net. Not all of the answers for improving health care will come from healthcare organisations. For instance, 
hospitals and clinics could eliminate many of the waits and delays for patients and staff at the moment. The resources to do so are sufficient and in hand, but the current models of scheduling and flow management in health care do not work. They are systems with long delays built right into them. The best models for achieving continuous flow lie in other industries, and healthcare people must venture beyond the boundaries of their profession to discover them. ${ }^{14}{ }^{15}$

\section{Run a test of change}

When children are learning to ride a bike, thinking about the task is not enough. They must also practice until they learn the required muscle movements and techniques, and make them on their own. Improving health care is no different. Improvement requires testing changes, for the purpose of learning and adapting them. In the jargon of the model for improvement, this is the plan-do-study-act (PDSA) cycle, running real world tests of change and learning from what happens. To join in improvement, the healthcare workforce must have the skills to run many PDSA tests, assess the results, and build on what they learn.

A handful of basic rules govern effective use of the PDSA cycle. Usually, the tests are best done in teams, so that learning takes place among a whole group. They must be adapted to local conditions, which will not be the same in Maine as they are in Manchester or Minnesota. A key rule is that small and frequent tests are better than big and slow ones. In formal science, tests tend to be large scale and take a lot of time. That is often as it should be. In real time science, however, the best tests are small, quick, and frequent. Real change requires many tests, performed over and over again. When such tests are linked to powerful new designscomprehensive models of a new system of care-they can accumulate into truly new levels of performance for the system as a whole.

Another key rule in improvement is to be open and honest about "failed" tests, which are often the most valuable ones. It is natural for human beings, especially self critical healthcare professionals, to want to forget about experiments that do not work. But any scientist knows that learning from failure is just as important as learning from success. Negative experiments rule out attractive but unproductive hypotheses, identify unexpected correlations and consequences, and make the experimenter smarter.

\section{FACING REALITY (ONCE MORE)}

A truly post-Taylor healthcare workforce would be one far more capable of improving systems of care. It would have new and better skills in setting aims, measuring progress, finding alternatives to familiar ways of working, and running many rapid tests of change informed by bold and important new models of the system as a whole. But, so far, the first step toward that vision, facing the reality of our current flaws, remains a major stumbling block. Two Japanese words encapsulate the problem especially well: taseki and jiseki.

Taseki means "the burden is yours", it is passing the buck. For lower performers, the first reaction is, often, the data are wrong. If that line of defence fails, the second reaction is usually, the data are right, but it's not a problem. That discarded, it is then only a small step to the third stage, which is, the data are right, and it's a problem-but it's not my problem! Taseki is a way of saying, "the dog ate my homework, it is not my fault, and it is not my responsibility".

The Japanese opposite, jiseki, means "the responsibility is mine". It means I've got the ball, the buck stops here. From the point of view of jiseki, blaming cost constraints, the environment, the regulators, or anybody else for the current defects in health care is not an acceptable plan. Jiseki is a tough mindset. Accepting responsibility for gaps, for

\section{Key messages}

- Current strategies for developing the healthcare workforce are based on outmoded theories of control and standardisation of work.

- Quality is a system property; if we want better results, we have to change the system.

- We need to harness the imagination and participation of the workforce in reinventing the system.

- The workforce needs to know how to set bold aims, measure progress, find alternative designs for work, and test changes rapidly and informatively.

- Change begins with a shift in attitude from taseki (the burden is yours) to jiseki (the responsibility is mine).

example, can be the front door to feeling guilty. Jiseki requires trust in oneself, belief in one's own worthiness, intention, and capacity to improve. It requires that failures be embraced because of what they can teach. Psychologically, taseki is much easier!

Health care in the Western world has an unprecedented opportunity to improve. Modern information systems, better evaluative sciences, and consumerism have converged to hold a mirror up to its nature, and, for the first time in history, to generate a social consciousness that our precious systems of care are not achieving what they could and should. Daylight has arrived.

What we do with that opportunity will depend on the theory on which we act. We can tighten the ropes, celebrate Taylorism, and achieve a modicum of standardisation and stop there, small improvements at a high price in spirit.

Or we can leapfrog Taylorism-keeping only the manuals we really need-and invest in a workforce of imaginative, inspired, capable, and (dare I say it) joyous people, invited to use their minds and their wills to cooperate in reinventing the system, itself. The investment, if it is to be effective, must be real. Doctors, nurses, pharmacists, therapists, technicians, managers, and executives (everyone) will need to acquire and refine their capacities to set aims, measure and interpret results, search for unfamiliar and promising alternatives to the status quo, and test those alternatives rapidly, carefully, and constantly. They will need to do so together, in teams, to welcome failures as informative, to celebrate successes as collective, and to feel the excitement of jiseki because of the meaning it adds to their lives and the peace it offers in their souls. A workforce so nobly engaged deserves no less.

\section{ACKNOWLEDGEMENTS}

This paper was first presented at the Second Asia Pacific Forum on Quality Improvement in Health Care, Singapore, September 2002. A similar paper will appear as a chapter, Building trust in the health care environment, in the forthcoming book, The public's health: a matter of trust, edited by DA Shore (Harvard University Press: Cambridge, MA, in press).

The author wishes to thank Frank Davidoff, Jane Roessner, and Val Weber for extensive help in revising and editing this manuscript.

\section{Author's affiliation}

D M Berwick, Institute for Healthcare Improvement, 375 Longwood Avenue, 4th Floor, Boston, MA 02215, USA

\section{REFERENCES}

1 Institute of Medicine Committee on Quality of Health Care in America. Crossing the quality chasm: a new health system for the 21 st century. Washington, DC: National Academy Press, 2001. 
2 Chassin MR, Galvin RW. The urgent need to improve health care quality. Institute of Medicine National Roundtable on Health Care Quality. JAMA 1998;280(11):1000-05.

3 Cystic Fibrosis Foundation. Patient Registry 2000 Annual Report. Bethesda, MD, September 2001

4 Institute for Healthcare Improvement. Move your dot: measuring, evaluating, and reducing hospital mortality rates. Boston, MA: Institute for Healthcare Improvement, 2003

5 Womack JP, Jones DT. Lean thinking: banish waste and create wealth in your organization. New York, NY: Simon \& Schuster, 1996.

6 Berwick DM. A primer on leading the improvement of systems. BMJ 1996;312:619-22.

7 Nolan TW. Understanding medical systems. Ann Intern Med 1998;128(4):293-8

8 Taylor FW. The principles of scientific management. Norcross, GA: Engineering and Management Press, 1998.
9 Eichorn JH, Cooper JB, Cullen DJ, et al Standards for patient monitoring during anesthesia at Harvard Medical School. JAMA 1986;256(8): 1017-20.

10 Berwick DM, Nolan TW. Physicians as leaders in improving health care. Ann Intern Med 1998;128(4):289-92.

11 Langley GJ, Nolan KM, Nolan TW, et al. The improvement guide: a practical approach to enhancing organizational performance. San Francisco: JosseyBass, 1996.

12 Berwick DM. Controlling variation in health care: a consultation from Walter Shewhart. Med Care 1991;20(12):1212-25.

13 Weick KE, Sutcliffe KM. Managing the unexpected: assuring high performance in an age of complexity. San Francisco: Jossey-Bass, 2001.

14 Murray M, Berwick DM. Advanced access: reducing waiting and delays in primary care. JAMA 2003;289(8):1035-40.

15 Goldratt EM. The goal: a process of ongoing improvement. New York: North River Press, 1992. 